\title{
Optimization and Production of Probiotic and Antimycotoxin Yeast Biomass Using Bioethanol Industry Waste via Response Surface Methodology
}

\author{
Analía S Fochesato ${ }^{1,2}$, Miguel A Galvagno ${ }^{3}$, Cecilia Dog ${ }^{1,2}$, Patricia Cerrutti³ ${ }^{3}$ María L González Pereyra ${ }^{1,2}$, \\ Marcelo Flores ${ }^{4}$ and Cavaglieri $\mathrm{L}^{1,2 *}$ \\ ${ }^{1}$ Department of Microbiology and Immunology, National University of Río Cuarto, Argentina
}

${ }^{2}$ National Council of Scientific and Technical Research (CONICET), Argentina

${ }^{3}$ University of Buenos Aires, Argentina

${ }^{4}$ Department of Industries, National University of Río Cuarto, Argentina

Submission: December 12, 2017; Published: January 19, 2018

*Corresponding author: Lilia Cavaglieri, Department of Microbiology and Immunology, National University of Río Cuarto, Route 36km 601, 5800 Río Cuarto, Córdoba, Argentina, Fax: 54-358-4676231; Tel: 54-358-4676231; Email: lcavaglieri@exa.unrc.edu.ar

Abstract

Saccharomyces cerevisiae RC016 presents probiotic and mycotoxin adsorbent properties for use as feed additive. The improvement of S. cerevisiae RC016 biomass production using an agro-industrial waste such as Dried Distillers' Grains and Solubles (DDGs) that pollute the environment can contribute to sustainable development of the process and reduce the costs of large-scale production. In order to avoid the obstruction of the fermentor's stirring mechanism with solid particles a novel pretreatment of DDGs was conducted to concentrate carbon sources levels. The design of experiments were performed using four factor-three-level Box-Behnken design (carbon source concentration, nitrogen source concentration, yeast extract concentration and incubation time) coupled with response surface methodology to evaluate the interaction between two factors in order to determine the optimum process conditions. A quadratic model was suggested for the prediction of biomass production. The F-value and p-value of the model indicated that it was statistically significant at 95 percent confidence interval. In addition, $\mathrm{R}^{2}$ value of the model indicated an acceptable accuracy. The results were validated at bioreactor level showing that the specific growth rate on the optimized medium $\left(0.34 \mathrm{~h}^{-1}\right)$ increased $112.5 \%$ compared to the initial non-optimized medium $\left(0.16 \mathrm{~h}^{-1}\right)$, the duplication time showed a decrease of $52.9 \%$. Optimization enabled productivity $\left(0.451 \mathrm{gL}^{-1} \mathrm{~h}^{-1}\right)$ nine times higher than the initial one $\left(0.062 \mathrm{gL}^{-1} \mathrm{~h}^{-1}\right)$, thus $65 \%$ more biomass was obtained $\left(5.20 \mathrm{gL}^{-1}\right)$. The use of biomass DDGse derived from bioethanol production promotes the sustainable and green way of biomass production.

Keywords: Biomass production; Bioethanol industry waste; distillers' grains and solubles; Saccharomyces cerevisiae

\section{Introduction}

Distillers dried grains with solubles (DDGs) is the main co-product of ethanol production. It is a waste product from this industry, commonly used as a low-cost animal feed. After conversion of grain starch to ethanol during fermentation, there is an increase of all nutrients than about three times more protein, fat, vitamins, minerals and fibre. Its utilization as a feed ingredient is well documented as both, energy and a protein supplement (U.S. Grains Council).

Application of agro-industrial waste and co-products in bioprocesses provides an alternative way to replace the refined and costly raw materials. In addition, the bulk use of agroindustrial waste residues will help to solve environmental issues. Microbial biomass production by using DDGs is an alternative of great interest for reuse of this industrial byproduct. It can serve as a protein concentrate as well as energy source for microbial growth. Energy provided by DDGs is obtained from oil since starch is removed from grains in the ethanol production process. One of the main obstructions in the large-scale production of yeasts and their products is the cost of the raw materials. Therefore, efficient and profitable factoryscale processes need to obtain the highest biomass yield with the minimal cost. Economic evaluation of the yeast production process has suggested that the major contributor to the overall cost is the cost of carbon source. Thus, it is desirable to produce yeast biomass from alternative low-cost carbon sources derived from other industries [1]. 
Probiotics are live microorganisms which when administered in adequate amounts confer a health benefit on the host [2]. They exert beneficial effects on the host by providing nutrients and enzymes that contribute to digestion, inhibiting pathogenic microorganisms, enhancing growth and immune responses $[3,4]$. Saccharomyces cerevisiae RC016 is a probiotic strain isolated from pig intestine that is able to adsorb several mycotoxins such as aflatoxin B1, zearalenone, fumonisin B1 and ochratoxin A, survive under gastrointestinal conditions, enhance animal weight gain and performance and promote beneficial properties to the host. It is also considered a generally regarded as safe (GRAS) microorganism and has shown absence of genotoxicity and cytotoxicity in vivo [5-7]. Therefore, its application as a feed additive intended for production animals is very promising and entails minimal risk.

Feed additives' industry requires standardized processes to produce large amounts of the selected yeasts to obtain high quality reproducible products to ensure biological effect. To achieve high yeast yields, it is a prerequisite to design a proper production medium in an efficient fermentation process. Therefore, the viability of a biotechnological process includes the strategic optimization of a culture medium using low cost raw materials. It is important to select key parameters from a large number of factors and also their interactions. Several statistical experimental designs have been used for optimizing fermentation variables [8,9]. Plackett- Burman design [10] is a well-established and widely used statistical model for screening and selecting critical culture variables, while response surface methodology (RSM) provides important information regarding the optimum level of each variable along with its interactions with other variables and their effects on product yield [11,12]. The aim of the present work was to study the culture conditions for probiotic-mycotoxin adsorbent $S$. cerevisiae RC0016 biomass production using DDGs as low-cost agro-industrial waste.

\section{Materials and Methods}

\section{Yeast strain and cultural conditions}

Saccharomyces cerevisiae RC016 was isolated from pig intestine and deposited in collection centre of the Universidad Nacional de Río Cuarto, Argentina. Stock cultures were maintained at $-80{ }^{\circ} \mathrm{C}$ in $30 \%(\mathrm{v} / \mathrm{v}$ ) glycerol. Working cultures were prepared from frozen stocks by two transfers in yeast extract-peptone-dextrose (YPD) broth (5g yeast extract, $5 \mathrm{~g}$ peptone, $40 \mathrm{~g}$ dextrose, $1000 \mathrm{ml}$ water) and incubation at 28 ${ }^{\circ} \mathrm{C}$ for $24 \mathrm{~h}$ on an orbital shaker (180rpm). Morphological and molecular characteristics of this strain were informed by Armando et al. [11].

\section{Bioethanol industry waste composition and pretreatment}

The DDGs (used as carbon source) centesimal composition is informed in Table 1. DDGs was obtained from a local bioethanol producing plant. In order to avoid the obstruction of the fermentor's stirring mechanism with solid DDGs particles and concentrate the level of carbon sources, a DDGs' extract (DDGse) was prepared by adding water $(300 \mathrm{ml}+75 \mathrm{~g}$ DDGS) to obtain a $25 \%$ DDGse that was left at fluent steam for $20 \mathrm{~min}$ and then filtered. The extract was then autoclaved at $121{ }^{\circ} \mathrm{C}, 1 \mathrm{~atm}$ for $15 \mathrm{~min}$. Adequate volumes of this extract were used to formulate culture media at 14, 21 and 28\% (Plackett-Burman design) and at 10, 20 and 30\% (Box-Behnken design).

Table 1: Dried distillers' grains and solubles (DDGs) centesimal composition.

\begin{tabular}{|c|c|}
\hline \multicolumn{2}{|c|}{ Dried Distillers' Grains And Solubles (Ddgs) } \\
\hline Components & Percentage \\
\hline Dry matter & 35.97 \\
\hline Water & 64.03 \\
\hline Total protein & 10.52 \\
\hline Total fats & 4 \\
\hline Total fibre & 3.08 \\
\hline Neutral detergent fibre (NDF) & 3.76 \\
\hline Acid detergent fibre (ADF) & 8.98 \\
\hline Starch & 1.79 \\
\hline Sulfur & 0.23 \\
\hline Phosphorus & 0.32 \\
\hline Ashes & 2.28 \\
\hline
\end{tabular}

\section{Culture conditions and experimental designs for biomass production}

Culture medium was designed using the following factors: DDGse as carbon source, urea as nitrogen source, and YE as vitamin supply. Saccharomyces cerevisiae biomass production was performed in shaken Erlenmeyer flasks and then validated in an aerated-agitated fermentor. For Erlenmeyer flasks' inoculation, a loopful of a S. cerevisiae RC016 culture maintained at $4{ }^{\circ} \mathrm{C}$ on an YPD agar slant was transferred to $10 \mathrm{ml}$ YPD broth (pH 4.5-5.5) contained in $100 \mathrm{ml}$ Erlenmeyer flasks (flask volume to medium volume ratio was $10: 1$ ) and incubated at $28 \pm 1{ }^{\circ} \mathrm{C}$ for $24 \mathrm{~h}$ at $180 \mathrm{rpm}$ in an orbital shaker.

For the fermentor assay, the culture media optimized in Erlenmeyer flasks was validated by carrying out batch fermentations in an aerated-mechanically stirred $5 \mathrm{~L} \mathrm{BioFlo}{ }^{\mathrm{TM}}$ 2000 fermenter (New Brunswick Scientific Co., Inc, Enfield, $\mathrm{CT}$, USA) equipped with $\mathrm{pH}$, temperature and dissolved oxygen concentration sensors. The $\mathrm{pH}$ was maintained between 4.5 and 5.5 units by adding $18 \mathrm{~N} \mathrm{H} 2 \mathrm{SO} 4$ or $20 \% \mathrm{w}, \mathrm{v}-1 \mathrm{Na} 2 \mathrm{CO}$. Dissolved oxygen concentration at the beginning of the experiment was $100 \%$ saturation. Foam production was controlled by the addition of Antifoam 289 (Sigma-Aldrich, St. Louis, MO, USA) defoamer. For both, flasks and fermentor assays, aliquots of $3 \mathrm{~mL}$ culture were withdrawn for kinetic and productive parameter determinations and growth curves were constructed. 
Table 2: Levels of factors tested by Plackett-Burman Design for the screening of significant variables affecting Saccharomyces cerevisiae RC016 biomass production.

\begin{tabular}{|c|c|c|c|}
\hline \multirow{2}{*}{ Factors } & \multicolumn{3}{|c|}{ Levels } \\
\cline { 2 - 4 } & $\mathbf{- 1}$ & $\mathbf{0}$ & $\mathbf{1}$ \\
\hline DDGse* (\%) $^{*}$ & 14 & 21 & 28 \\
\hline Urea (\%) & 0 & 0.25 & 0.5 \\
\hline YE** $\left.^{*} \%\right)$ & 0.5 & 0.75 & 1 \\
\hline Time (h) & 1 & 7 & 13 \\
\hline
\end{tabular}

${ }^{*}$ DDGse: Dried distillers' grains and solubles extract, ${ }^{*}$ YE: yeast extract.

A Plackett-Burman screening design was used to select the main medium constituents influencing S. cerevisiae RC016 biomass production according to Plackett \& Burman [10]. The model was set up for four previously mentioned factors for the culture media, with two coded levels $(-1$ and +1$)$ and a centre point $(0)$, and was run to evaluate the linear effects of carbon source concentration (DDGse) (b1), nitrogen source concentration (urea) (b2), YE concentration (b3) and incubation time (b4) (Table 2).

The results were fitted with the first-order model

$$
Y=b_{0}+\sum b_{i} x_{i}
$$

Where $\mathrm{Y}$ is the predicted response, b0 and bi are constant coefficients and $x i$ is the coded independent factor.

Table 3: Levels of factors tested by Box-Behnken designs for the optimization of Saccharomyces cerevisiae RC016 biomass production.

\begin{tabular}{|c|c|c|c|}
\hline \multirow{2}{*}{ Factors } & \multicolumn{3}{|c|}{ Levels } \\
\cline { 2 - 4 } & $\mathbf{- 1}$ & $\mathbf{0}$ & $\mathbf{1}$ \\
\hline DDGse* (\%) & 10 & 20 & 30 \\
\hline Urea (\%) & 0 & 0.5 & 1 \\
\hline Time (h) & 12 & 18 & 24 \\
\hline
\end{tabular}

*DDGse: Dried distillers' grains and solubles extract.

A Box-Behnken design (BBD) [13] of Response Surface Methodology (RSM) was used to optimize the three most Table 4: Statistical analysis (ANOVA) of the model applied for Saccharomyces cerevisiae RC016 biomass production in a DDGs extract (DDGse) based medium. significant factors (carbon source, nitrogen source, YE) for enhancing biomass of S. cerevisiae RC016, screened by PlackettBurman design. Three settings for each of three factor levels were used to evaluate the quadratic effects and two-way interactions among the variables DDGse, urea concentration and time (Table 3).

A second-degree model was used to fit the response to the independent variables according to the equation:

$$
Y=\beta_{0}+\sum_{i=1}^{k} \beta_{i} x_{i}+\sum_{j=2}^{k} \sum_{i=1}^{j-1} \beta_{i j} x_{i} x_{j}+\sum_{i=1}^{k} \beta_{i i} x_{i}^{2}
$$

Where $Y$ is the predicted response, $x i x j$ are the input variables that influence the response variable $y, \beta 0$ is the intercept, $\beta \mathrm{i}$ is the ith lineal coefficient, $\beta$ ii is the ith quadratic coefficient and $\beta \mathrm{ij}$ is the ijth interaction coefficient. Statistical and numerical analyses were carried out by means of the analysis of variance (ANOVA) and multiple regressions using Essential Experimental Design v. 2.214 software.

\section{Analytical determinations}

Biomass production was monitored evaluating CFU ml-1 by the standard plate count method on YPD agar and then, multiplied by an adequate factor to transform these values into biomass values in grams.

\section{Results}

\section{Screening of essential culture conditions for biomass production}

Fifteen trials were conducted to examine the effect of four variables for the production of yeast biomass using the PlackettBurman design, a powerful method for detecting significant variables. The coefficient R2 of the first-order model for the DDGse based medium was 0.785 , indicating that only $21.5 \%$ of the variability in the response could not be explained by the model. The adjusted R2 was 0.699 , indicating the linear model fits properly. The $\mathrm{F}$ value demonstrated a high significance for the regression. ANOVA was used to identify the effect of four factors on yeast biomass production.

\begin{tabular}{|c|c|}
\hline \multicolumn{2}{|c|}{ Summary } \\
\hline$|\mathrm{R}|$ & 0.886 \\
\hline $\mathrm{R} 2$ & 0.785 \\
\hline R2 adjusted & 0.699 \\
\hline Standard Error & 0.182 \\
\hline \# Points & 15 \\
\hline PRESS & 0.56 \\
\hline R2 for Prediction & 0.635 \\
\hline Durbin-Watson d & 2.138 \\
\hline First Order Autocorrelation & -0.092 \\
\hline Coefficient of Variation & 2.352 \\
\hline
\end{tabular}




\begin{tabular}{|c|c|c|c|c|c|c|c|}
\hline \multicolumn{4}{|c|}{ Precision Index } & \multicolumn{4}{|c|}{8.582} \\
\hline \multicolumn{8}{|c|}{ ANOVA } \\
\hline Source & SS & SS\% & MS & $\mathrm{F}$ & F Signif & \multicolumn{2}{|c|}{$\mathrm{df}$} \\
\hline Regression & 1.205 & 78 & 0.301 & 9.123 & 0.00227 & \multicolumn{2}{|c|}{4} \\
\hline Residual & 0.33 & 22 & 0.03301 & & & \multicolumn{2}{|c|}{10} \\
\hline LOF Error & 0.275 & 18 (83) & 0.03929 & 2.1382 & 0.286 & \multicolumn{2}{|c|}{7} \\
\hline Pure Error & 0.05512 & $4(17)$ & 0.01837 & & & \multicolumn{2}{|c|}{3} \\
\hline Total & 1.535 & 100 & & & & \multicolumn{2}{|c|}{14} \\
\hline & & $P$ value & Std Error & $-95 \%$ & $95 \%$ & t Stat & VIF \\
\hline b0 & 7.346 & $3.40 \mathrm{E}-11$ & 0.241 & 6.809 & 7.884 & 30.45 & \\
\hline DDGse* & 7048611 & 0.00448 & 1932153 & $3.00 \mathrm{E}+06$ & $1.00 \mathrm{E}+07$ & 3.648 & 1 \\
\hline UREA & $-2.5 \mathrm{E}+07$ & 0.14 & 15457227 & $-6.00 \mathrm{E}+07$ & $1.00 \mathrm{E}+07$ & -1.603 & 1 \\
\hline $\mathrm{YE}^{* *}$ & 0.0401 & 0.852 & 0.21 & -0.427 & 0.508 & 0.191 & 1 \\
\hline Time & 0.05277 & 0.000126 & 0.00874 & 0.03329 & 0.07225 & 6.036 & 1 \\
\hline
\end{tabular}

*DDGse: Dried distillers' grains and solubles extract; **YE: yeast extract.

Table 4 shows that DDGse and urea concentrations were the most significant factors $(\mathrm{P}<0.05)$ that were selected for further optimization to obtain a maximum response. The equation obtained for cell growth was:

$\mathrm{Y}(\mathrm{CFU} / \mathrm{mL})=7.346+7048611.111 * \mathrm{DDGSE}-$ 24777777.78*UREA + 0.05277*Time

(*The P-values for regression coefficients in bold characters were significant at $\mathrm{P}<0.05$ )

\section{Selected culture conditions optimization of for biomass production}

Based on the results obtained from the Plackett-Burman design, the major factors that influenced S. cerevisiae RC016 biomass production were selected. The BBD was applied to study the interaction of the selected variables, to estimate the quadratic effects and to determine the optimal quantitative values of the studied parameters in order to maximize the response.

The coefficient of determination R2 (0.898) for the DDGse based medium indicated that only $10.2 \%$ of the variability in the response could not be explained by the model. The statistical significance of the equation model was evaluated by ANOVA $F$ test (Table 5). Values 'Prob>F less than 0.05 indicated that the terms of the model were significant. The unadjusted F-value of 0.317 (not significant) may occur due to noise. The RSM was fitted with the second-order polynomial equation:

Table 5: Statistical analysis (ANOVA) of the model applied for Saccharomyces cerevisiae RC016 biomass production in a DDGs extract (DDGse) based medium.

\begin{tabular}{|c|c|c|c|c|c|c|}
\hline \multicolumn{7}{|c|}{ Summary } \\
\hline$|\mathrm{R}|$ & & & \multicolumn{4}{|c|}{0.948} \\
\hline $\mathrm{R}^{2}$ & & & \multicolumn{4}{|c|}{0.898} \\
\hline $\mathrm{R}^{2}$ adjusted & & & \multicolumn{4}{|c|}{0.715} \\
\hline Standard Error & & & \multicolumn{4}{|c|}{0.248} \\
\hline \# Points & & & \multicolumn{4}{|c|}{15} \\
\hline PRESS & & & \multicolumn{4}{|c|}{3.96} \\
\hline $\mathrm{R}^{2}$ for Prediction & & & \multicolumn{4}{|c|}{-0.313} \\
\hline Durbin-Watson d & & & \multicolumn{4}{|c|}{2.504} \\
\hline First Order Autocorrelation & & & \multicolumn{4}{|c|}{-0.354} \\
\hline Collinearity & & & \multicolumn{4}{|c|}{0} \\
\hline Coefficient of Variation & & & \multicolumn{4}{|c|}{3.174} \\
\hline Precision Index & & & \multicolumn{4}{|c|}{9.242} \\
\hline \multicolumn{7}{|c|}{ ANOVA } \\
\hline \multicolumn{2}{|l|}{ Source } & $\mathrm{SS} \%$ & MS & \multirow{3}{*}{$\begin{array}{c}\mathrm{F} \\
4.91 \\
\end{array}$} & F Signif & $\mathrm{df}$ \\
\hline Regression & 2.713 & 90 & 0.301 & & 0.04725 & 9 \\
\hline Residual & & 10 & 0.0614 & & & 5 \\
\hline
\end{tabular}


Advances in Biotechnology \& Microbiology

\begin{tabular}{|c|c|c|c|c|c|c|c|}
\hline LOF Error & \multicolumn{2}{|c|}{0.238} & $8(78)$ & 0.07936 & 2.3023 & 0.317 & 3 \\
\hline Pure Error & \multicolumn{2}{|c|}{0.06894} & $2(22)$ & 0.03447 & & 2 \\
\hline Total & \multicolumn{2}{|c|}{3.02} & 100 & & & & \\
\hline & & P value & Std Error & $-\mathbf{9 5 \%}$ & $\mathbf{9 5 \%}$ & t Stat & VIF \\
\hline b0 & 7.298 & 0.00505 & 1.533 & 3.358 & 11.24 & 4.762 & 0.289 \\
\hline DDGse & 0.01889 & 0.784 & 0.06537 & -0.149 & 0.187 & 55.67 \\
\hline Urea & 0.4 & 0.718 & 1.046 & -2.29 & 3.09 & 0.382 & 35.67 \\
\hline Time & 0.07075 & 0.629 & 0.138 & -0.283 & 0.425 & 0.514 & 89 \\
\hline DDGse* DDGse & -0.00209 & 0.166 & 0.00129 & -0.00541 & 0.00122 & -1.623 & 35.68 \\
\hline Urea*Urea & -1.794 & 0.01769 & 0.516 & -3.12 & -0.468 & -3.478 & 9.678 \\
\hline Time*Time & -0.00185 & 0.628 & 0.00358 & -0.01105 & 0.00736 & -0.515 & 79.01 \\
\hline DDGse*Urea & 0.05604 & 0.0732 & 0.02478 & -0.00765 & 0.12 & 2.262 & 11 \\
\hline DDGse*Time & 0.00175 & 0.436 & 0.00206 & -0.00356 & 0.00705 & 0.846 & 27 \\
\hline Urea*Time & -0.02906 & 0.513 & 0.0413 & -0.135 & 0.0771 & -0.704 & 21 \\
\hline
\end{tabular}

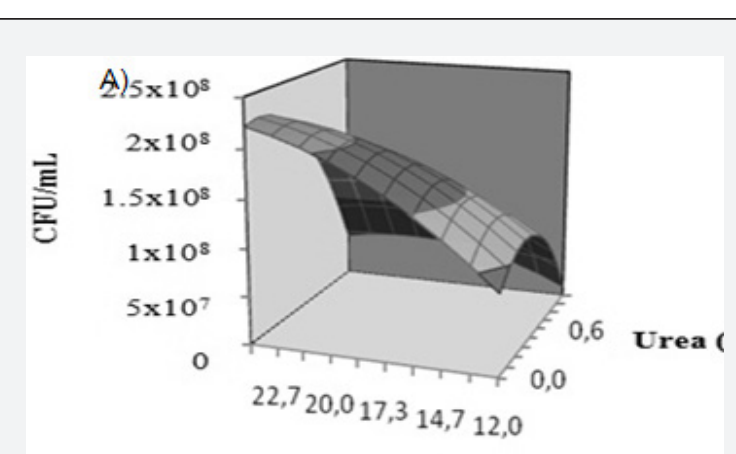

Time (h)

B)
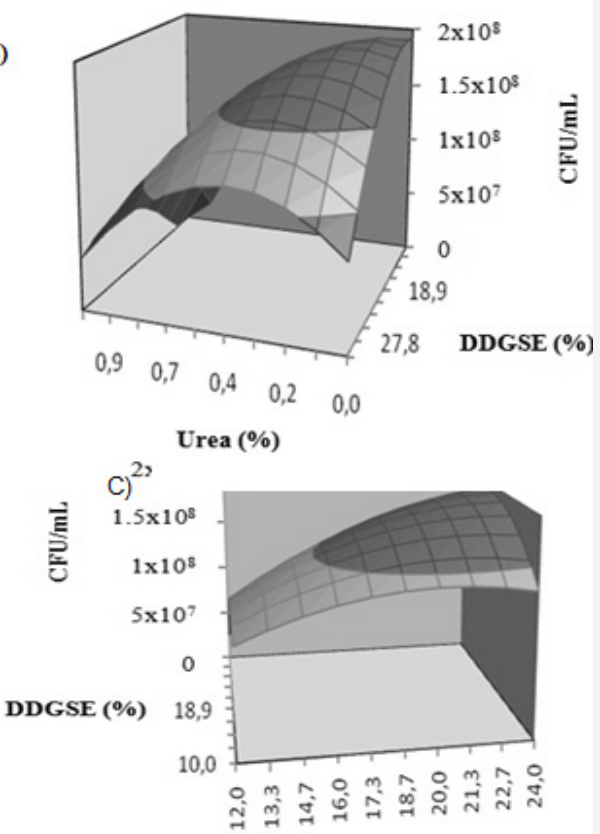

Time (h)

Figure 1: Response surface curve for biomass of $S$. cerevisiae RC016 showing the interaction between A) Urea and Time; B) Urea and DDGse; (C) Time and DDGse. The grey colour scale shows the levels of biomass production by the yeast.

$\mathrm{Y}(\mathrm{CFU} / \mathrm{mL})=7.298+0.01889 * \mathrm{DDGse}+0.400 *$ Urea +
0.07075*Time - 0.00209*DDGse* DDGse - 1.794*Urea*Urea - $0.00185^{*}$ Time*Time $+0.05604^{*}$ DDGse*Urea $+0.00175^{*}$ DDGse*Time $-0.02906 *$ Urea*Time

The model predicts that the optimal values of the three most significant variables were DDGse $=18.9 \%(\mathrm{~m} / \mathrm{v})$; Urea $=0 \%(\mathrm{~m} / \mathrm{v}) ; \mathrm{YE}=1 \%(\mathrm{~m} / \mathrm{v})$ and incubation time $=21.3 \mathrm{~h}$. The response surface curves are shown in Figure 1.

\section{Validation of the selected culture conditions in bioreactors}

Table 6: Comparison of kinetic parameters (specific growth rate $(\mu \mathrm{x}))$ and duplication time $(\mathrm{td})$ and productive parameters (maximum productivity ( $\mathrm{gl}-1 \mathrm{~h}-1)$ ) and maximum production ( $\mathrm{gl}-1)$ of Saccharomyces cerevisiae RC016 in shaken flasks and bioreactor using initial and optimized media.

\begin{tabular}{|c|c|c|}
\hline $\begin{array}{c}\text { Kinetic and Productive } \\
\text { Parameters }\end{array}$ & Initial Media & Optimized Media \\
\cline { 2 - 3 } & Shaken Flasks & Bioreactor \\
\hline$\mu$ máx $\left(\mathrm{h}^{-1}\right)$ & 0.16 & 0.34 \\
\hline $\mathrm{Td}(\mathrm{h})$ & 4.33 & 2.04 \\
\hline Productivitymax $\left(\mathrm{g} \mathrm{L}^{-1} \mathrm{~h}^{-1}\right)$ & 0.062 & $0.451 \pm 0.065(11 \mathrm{~h})$ \\
\hline Biomassmax $\left(\mathrm{g} \mathrm{L}^{-1}\right)$ & $1.83(48 \mathrm{~h})$ & $5.20(11 \mathrm{~h})$ \\
\hline
\end{tabular}

Once the most significant variables and their optimum values were obtained, validation in bioreactor was performed in order to confirm the optimized culture conditions. Mechanical stirring to produce yeast biomass in bioreactor allows a greater homogenization of the cells in contact with the medium thereby increasing oxygen transfer and mass. Kinetic and productive parameters are shown in Table 6, the biomass production of S. cerevisiae RC016 improved significantly in the optimized media and in bioreactor compared with initial media in Erlenmeyers. The growth rate significantly increased (112.5\%) whereas duplication time was reduced 53.2\%.

\section{Discussion}

The viability of a biotechnological process includes a strategic analysis for reducing production costs in optimizing biomass production. The design of the culture medium is one 
of the most important tasks in biological technology. Winkler et al. [14] stated that within the total cost of biotech products, raw materials can represent between 30 and $80 \%$. The composition of the culture medium also has to meet all the nutritional requirements of the microorganism. Economic evaluation of the production process of yeast suggests that the main contributor to the overall cost is the carbon source. For the formulation of an industrial culture medium it is necessary that it meets all nutritional characteristic requirements, allowing good growth of microorganisms. They have to be available on the market or otherwise be obtained as by product of some industrial process, in order to be inexpensive to manufacture. YPD medium is widely used as a substrate to obtain S. cerevisiae biomass; it is a synthetic, commercial, processed and enriched medium with glucose as carbon sources and nitrogen sources as yeast extract and peptone [15]. However, it is a highly expensive culture medium when large-scale biomass is needed to obtain. Therefore, it is desirable to produce yeast biomass from cheap carbon sources or waste products, such as cane molasses or sugar residues of bioethanol production. In this work, with the purpose of minimize large-scale production costs and promote sustainable biomass development the use inexpensive substrates such a waste obtained from the bioethanol production was used. This substrate, DDGse has nutritional and economic advantages due to its high protein content as nitrogen sources, yeasts, minerals, group B vitamins.

When a response or set of responses of interest are influenced by several variables, the levels of these variables must be optimized simultaneously to achieve the best system performance [16]. The use of statistical experimental designs methodology in shaken flasks allowed reaching the best nutritional conditions for the culture medium for increasing biomass production. Li et al. [17] used the same methodology we used, for the production of the yeast C. utilis in bamboo wastewater that resulted in an overall 1.7-fold increase compared with that using the original conditions in shake-flask cultivation. In the present work, in DDGse optimized conditions the biomass production increased nine fold.

The most significant variables and their optimal ranges were 18.9\% DDGse and YE 1\%. In the present work, these conditions were evaluated at bioreactor level and significant improvements were obtained for the biomass production of S. cerevisiae RC0016 [18]. Other authors have shown the use of different waste substrates for biomass production. Choi and Park (2003) investigated Chinese cabbage waste as a substrate for microbial biomass production of four species of yeast included S. cerevisiae and suggested that juice from waste Chinese cabbages could be used to produce microbial biomass proteins. Other researchers, Marova et al. [19] evaluated the influence of several wastes substrates such as non-processed whey and potato extract on the production of carotenoids by yeast strains and biomass. They demonstrated these substrates were adequate for yeast biomass production that could be directly used in feed industry as nutrition supplement [20]. Bioreactor validation showed good production growth and kinetic parameters. The highest growth rate $\left(0.34 \mathrm{~h}^{-1}\right)$ showed a $2.04 \mathrm{~h}$ duplication time and a high productivity $\left(0.45 \mathrm{gL}^{-1} \mathrm{~h}^{-1}\right)$.

\section{Conclusion}

Waste substrates can be used as medium component, which can in particular strains and conditions induce biomass production. Thus, low cost waste substrates could be used industrially biomass production. This study suggest that the large amount of waste DDGs, produced during bioethanol production, and overproduction can be used to generate S. cerevisiae RC0016 biomass to be applied in feed additive formulations reducing production costs of the final products. The use of this agroindustrial waste that pollutes the environment can contribute to sustainable development of the process and reduce the costs of large-scale production.

\section{Acknowledgement}

This work was supported by Agencia Nacional de Promoción Científica y Tecnológica (ANPCYT-PICT), Consejo Nacional de Promoción Científica y Técnica (CONICET) and Universidad Nacional de Río Cuarto (SECYT-UNRC).

\section{References}

1. Kent JA (2007) Handbook of Industrial Chemistry and Biotechnology. In: Chotani G, Dodge T, Gaertner A, Arbige M (Eds.), Chapter 30: Industrial Biotechnology: Discovery to Delivery. $\left(11^{\text {th }}\right.$ edn), Springer, Berlin, Germany.

2. FAO/WHO (2001) Health and nutritional properties of probiotics in food including powder milk and Live Lactic Acid Bacteria. Food and Agriculture Organization of the United Nations and World Health Organization Expert Consultation Report.

3. Balcázar JL, De Blas I, Ruiz-Zarzuela I, Cunningham D, Vendrell D, et al. (2006) The role of probiotics in aquaculture. Vet Microbiol 114(3-4): 173-186.

4. Verschuere L, Rombaut G, Sorgeloos P, Verstraete W (2000) Probiotic bacteria as biological control agents in aquaculture. Microbiol Mol Biol Rev 64(4): 655-671.

5. Armando MR, Pizzolitto RP, Dogi CA, Cristofolini A, Merkis C (2012) Adsorption of ochratoxin A and zearalenone by potential probiotic Saccharomyces cerevisiae strains and its relation with cell wall thickness. J Appl Microbiol 113(2): 256-264.

6. Dogi CA, Armando R, Ludueña R, Moreno de LeBlanc A, Rosa CA, et al. (2011) Saccharomyces cerevisiae strains retain their viability and aflatoxin $\mathrm{B}_{1}$ bi nding ability under gastrointestinal conditions and improve ruminal fermentation. Food Addit Contam 28(12): 17051711.

7. González Pereyra ML, Dogi C, Torres Lisa A, Wittouck P, Ortíz M, et al. (2014) Genotoxicity and cytotoxicity evaluation of probiotic Saccharomyces cerevisiae RC016: a 60-day subchronic oral toxicity study in rats. J Appl Microbiol 117(3): 824-833.

8. Xu CP, Kim SW, Hwang HJ, Yun JW (2002) Application of statistically based experimental designs for the optimization of exo-polysaccharide production by Cordyceps militaris NG3. Biotechnol Appl Biochem 36(2): 127-131.

9. Rao RS, Prakasham RS, Prasad KK, Rajesham SSPN, Sarma PN, et al. (2004) Xylitol production by Candida sp. parameter optimization 
using Taguchi approach. Proc Biochem 39(8): 951-956.

10. Plackett RL, Burman JP (1946) The design of optimum multifactorial experiments. Biometrika 33(4): 305-325.

11. Armando MR, Dogi CA, Pizzolitto RP, Escobar F, Peirano MS, et al (2011) Saccharomyces cerevisiae strains from animal environmental with aflatoxin $\mathrm{B}_{1}$ binding ability and antipathogenic bacteria influence in vitro. World Mycotoxin J 1: 59-68.

12. Gu SY, Ren J (2005) Process optimization and empirical modeling for electrospun poly (D, L-lactide) fibers using response surface methodology. Macromol Materials Engineer 290(11): 1097-1105.

13. Li XY, Liu ZQ Chi ZM (2008) Production of phytase by a marine yeast Kodamaea ohmeri BG3 in an oats medium: optimization by response surface methodology. Biores Technol 99(14): 6386-6390.

14. Ferreira SC, Bruns RE, Ferreira HS, Matos GD, David JM, et al. (2007) Box-Behnken design: An alternative for the optimization of analytical methods. Anal Chem Acta 597(2): 179-186.

15. Winkler M (1988) Optimisation and time profiling in fermentation process. In: Bushell ME (Ed.), Chapter 4: Computer applications in

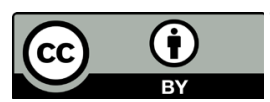

This work is licensed under Creative Commons Attribution 4.0 Licens

DOI: 10.19080/AIBM.2018.08.555727 fermentation technology progress in industrial microbiology. Volume 25, Elsevier, Amsterdam, Netherlands, pp. 91-150.

16. Castillo EEF, Forero SCS, Industrial M (2007) Evaluación de melaza de caña como sustrato para la producción de Saccharomyces cerevisiae. Trabajo de grado. Pontificia Universidad Javeriana. Facultad de ciencias básicas. Microbiología industrial. Bogota DC, Colombia.

17. Bezerra MA, Santelli RE, Oliveira EP, Villar LS, Escaleira LA (2008) Response surface methodology (RSM) as a tool for optimization in analytical chemistry. Talanta 76(5): 965-977.

18. Li X, Ouyang J, Xu Y, Chen M, Song X, et al. (2009) Optimization of culture conditions for production of yeast biomass using bamboo wastewater by response surface methodology. Biores Technol 100(14): 3613-3617.

19. Marova I, Carnecka M, Halienova A, Certik M, Dvorakova T, et al. (2012) Use of several waste substrates for carotenoid-rich yeast biomass production. J Environ Manage 95: 338-342.

20. http://www.grains.org/buyingselling/ddgs

\section{Your next submission with Juniper Publishers will reach you the below assets}

- Quality Editorial service

- Swift Peer Review

- Reprints availability

- E-prints Service

- Manuscript Podcast for convenient understanding

- Global attainment for your research

- Manuscript accessibility in different formats

( Pdf, E-pub, Full Text, Audio)

- Unceasing customer service

Track the below URL for one-step submission https://juniperpublishers.com/online-submission.php 